\title{
EXOGENOUS SURFACTANT TREATMENT BEFORE AND AFTER SIXTEEN HOURS OF ISCHEMIA IN EXPERIMENTAL LUNG TRANSPLANTATION
}

Bernard Hausen, $\mathrm{MD}^{\mathrm{a}}$

Roland Rohde, $\mathrm{MD}^{\mathrm{a}}$

Charles W. Hewitt, $\mathrm{PhD}^{\mathrm{b}}$

Frank Schroeder ${ }^{\text {a }}$

Maike Beuke ${ }^{\text {a }}$

Raj Ramsamooj, MD $^{\mathrm{b}}$

Hans-Joachim Schäfers, $M^{\mathrm{a}}$

Sponsor:

Hans-George Borst, MD
Objective: A syngeneic, acute, double lung transplant model in the rat was used to determine the impact of exogenous surfactant treatment on graft function after prolonged cold storage. Methods: The donor grafts were flush perfused, preserved for 16 hours, and then reperfused for 120 minutes. Untreated lungs served as controls (group I). In group II the recipient received a $200 \mathrm{mg} / \mathrm{kg}$ dose of surfactant (CuroSurf) before reperfusion. In groups III and IV, surfactant was administered before perfusion and harvesting (III, $20 \mathrm{mg} / \mathrm{kg} ; \mathrm{IV}, 200 \mathrm{mg} / \mathrm{kg}$ ). Serial measurements of graft pulmonary vascular resistance, alveolar-arterial oxygen difference, and compliance were obtained. Final graft assessment included weight gain and histologic study. Results: Repeated-measures analysis of variance showed significant improvement of graft performance in respect to compliance, alveolar-arterial oxygen difference, and pulmonary vascular resistance in donor surfactant treatment group IV $(200 \mathrm{mg} / \mathrm{kg})$ in comparison with recipient treatment (group II) and untreated controls (group I). Reducing the donor surfactant supplementation from $200 \mathrm{mg} / \mathrm{kg}$ to $20 \mathrm{mg} / \mathrm{kg}$ (group III) improved oxygenation and lung compliance as compared with untreated controls. Grafts in groups I and II had significantly more weight gain after 2 hours of reperfusion. Recipient treatment resulted in significantly more pulmonary hemorrhage in histologic sections. Conclusion: Donor treatment with exogenous surfactant is advantageous for preservation of graft function after extended ischemia. Positive effects may be seen with as little as $20 \mathrm{mg} / \mathrm{kg}$ of exogenous surfactant given before donor organ perfusion. (J Thorac Cardiovasc Surg 1997;113:1050-8)
$T_{\mathrm{c}}^{\mathrm{h}}$ he standard method of graft preservation in clinical lung transplantation consists of donor pretreatment with either prostaglandin $\mathrm{E}_{1}$ or prostaglandin $\mathrm{I}_{2}$, flush perfusion, and storage with EuroCollins solution at $4^{\circ} \mathrm{C}$. With this preservation

From the Division of Thoracic and Cardiovascular Surgery, Surgical Center, Hannover Medical School, Hannover, Germany, ${ }^{a}$ and the Division of Surgical Research, University of Medicine and Dentistry of New Jersey, Robert Wood Johnson Medical School at Camden, Camden, N.J. ${ }^{\text {b }}$

Read at the Seventy-sixth Annual Meeting of The American Association for Thoracic Surgery, San Diego, Calif., April 28-May 1, 1996.

Received for publication May 6, 1996; revisions requested June 11, 1996; revisions received Dec. 12, 1996; accepted for publication Feb. 18, 1997.

Address for reprints: Bernard Hausen, MD, Transplantation Immunology, Department of Cardiothoracic Surgery, Falk CVRB, Stanford University Medical Center, 300 Pasteur Dr., Stanford, CA 94304-5247.

Copyright (C) 1997 by Mosby-Year Book, Inc.

$0022-5223 / 97 \$ 5.00+0 \quad \mathbf{1 2 / 6 / 8 1 2 4 9}$ method, ischemic intervals up to 8 hours are presently considered compatible with good postoperative graft function. However, graft dysfunction may still be encountered despite apparently adequate preservation. Therefore various alterations in the method of preservation have been recommended on the basis of experimental data. ${ }^{1}$ Studies by Waldhausen, ${ }^{2}$ Veldhuizen, ${ }^{3}$ and their associates have shown severe alterations of pulmonary surfactant content and function resulting from ischemia and reperfusion. This phenomenon correlates with the absolute duration of ischemia ${ }^{3,4}$ and may be caused by the degree of static inflation during storage, ${ }^{5,6}$ surfactant deactivation through plasma proteins, ${ }^{7,8}$ or ischemic damage to type II alveolar ${ }^{9}$ cells. Consequently a decrease in lung compliance, functional residual capacity, and oxygen uptake may be encountered during reperfusion. ${ }^{10}$. If graft function is to be preserved after extended ischemia, surfactant depletion and dysfunction must be avoided. If this is not possible, surfactant replace- 
ment may be an alternative approach. Experimental investigations have shown benefits from replacement therapy with exogenous surfactant immediately before reperfusion. ${ }^{11}$

The following study was designed to test the hypothesis that timing of surfactant supplementation is critical for amelioration of reperfusion injury after lung transplantation. An additional aim was to test for a donor-response relation with the amount of surfactant used for donor treatment.

\section{Material and methods}

Male Lewis rats (350 to $400 \mathrm{gm}$ ) were obtained from Charles River Laboratories, Salzfeld, Germany, and all animals received humane care in compliance with the "Principles of Laboratory Animal Care" formulated by the "National Society for Medical Research" and the "Guide for the Care and Use of Laboratory Animals" prepared by the Institute of Laboratory Animal Resources and published by the National Institutes of Health (NIH Publication No. 86-23, revised 1985).

Experimental groups. The impact of exogenous surfactant treatment was evaluated in four experimental groups. The ischemic interval was limited to 16 hours in all groups. Untreated transplanted lungs served as controls (group I, $n=10$; no surfactant therapy). Animals of group II ( $n=$ 6) received a $200 \mathrm{mg} / \mathrm{kg}$ dose of exogenous surfactant (CuroSurf, Chiesa Farmaceutici, Parma, Italy) 15 minutes before reperfusion. In groups III $(n=10)$ and IV $(n=6)$, exogenous surfactant supplementation was added immediately after donor intubation as a bolus therapy into the donor trachea (group III, $20 \mathrm{mg} / \mathrm{kg}$; group IV, $200 \mathrm{mg} / \mathrm{kg}$ ). To determine the impact of timing the surfactant treatment, we compared groups I, II, and IV with each other. For dose-response analysis we compared groups III and IV.

Experimental procedure. The model of acute in situ double lung transplantation in the rat used in this experimental setting has been previously described in detail. ${ }^{12}$ After sedation, intubation, ventilation, and heparinization all lungs were flush perfused with a $60 \mathrm{ml} / \mathrm{kg}$ dose of low-potassium dextran solution ${ }^{13}$ (LPD, Perfadex) at $4^{\circ} \mathrm{C}$ and at a perfusion pressure of $20 \mathrm{~cm} \mathrm{H}_{2} \mathrm{O}$ during continued ventilation. The lungs were stored with static inflation $\left(26 \mathrm{~cm} \mathrm{H}_{2} \mathrm{O}\right.$ ) in low-potassium dextran solution at $4^{\circ} \mathrm{C}^{6}$ After an ischemic interval of 16 hours, the graft pulmonary trunk and left atrium were connected to the left pulmonary artery and vein of a syngeneic recipient rat with the use of two custom-designed T-shaped stents, one of which was equipped with a built-in Doppler probe (H-2R probe, Transonic Systems, Inc., Ithaca, N.Y.). Both stents included side ports for blood retrieval and pressure measurements (Fig. 1). The graft trachea was intubated with a 13-gauge cannula and the graft was ventilated separately with a volume-controlled respirator (Harvard Rodent Ventilator model 683; Harvard Apparatus Co., Inc., S. Natick, Mass.) at a tidal volume of $5 \mathrm{ml}$, a respiratory rate of 45 to 65 breaths/min, and a positive end-expiratory pressure of $3 \mathrm{~cm} \mathrm{H}_{2} \mathrm{O}$. The inspiratory oxygen concentration was selected at 1.0. After heparinization of the recipient, graft reperfusion was initiated.

The respiratory rate of the donor lung was adjusted according to analysis of blood gases in the left pulmonary vein, with a target carbon dioxide tension of 30 to $40 \mathrm{~mm}$ $\mathrm{Hg}$. Fluid was replaced with either blood or crystalloid fluids introduced through the pulmonary artery stent to ensure a pulmonary arterial pressure of $20 \mathrm{~mm} \mathrm{Hg}$ and a hematocrit value of $30 \%$ to $40 \%$. The donor lung was kept moist by intermittent topical application of warm saline solution. The $\mathrm{pH}$ measured in the pulmonary venous blood gases was titrated with $8.5 \%$ sodium bicarbonate to achieve a $\mathrm{pH}$ of 7.25 to 7.5 .

Measurements. The observation period for each experiment was limited to 120 minutes with serial measurements beginning 5 minutes after removal of the pulmonary artery clamp and then repeated every 20 minutes. Each measurement included the following parameters: left pulmonary arterial and venous blood gas analysis, left pulmonary arterial and left atrial blood pressure (PAP and LAP), isolated donor lung blood flow, and donor lung function (compliance, resistance). Derived parameters included alveolar-arterial oxygen difference (millimeters of mercury) and pulmonary vascular resistance (millimeters of mercury per milliliter per minute). The amount of intraalveolar edema was quantified after intratracheal suction before each measurement. At the end of the observation period the weight gain was determined (percent) and a histologic analysis performed.

Histology. At the end of the observation period the graft was flushed with formalin through the pulmonary artery and the airways via the trachea. The graft was then stored in formalin, cut, and stained with hematoxylin and eosin. Evaluation was performed in a blinded, semiquantitative fashion. The amount of interstitial edema, intraalveolar edema, granulocyte infiltration, and pulmonary hemorrhage was scored on a scale of 1 to 4 , with 1 being the least amount and 4 the maximum amount observed.

Statistical analysis. Data were analyzed with the Statistical Program of Social Sciences (SPSS for Windows Version 6.0.1, SPSS, Inc., Chicago, Ill.). All data are expressed as mean \pm standard error. Analysis of continuous data, such as compliance, resistance, alveolar-arterial oxygen difference, and pulmonary vascular resistance, was performed by repeated-measures analysis of variance (ANOVA).${ }^{14}$ The model used incorporated a fixed time effect, a fixed group effect, a time by group interaction effect, and a random animal effect. In addition, the change over time was statistically analyzed with this model. For multiple comparisons the Bonferroni adjustment was incorporated. The group interaction effect will be reported only when found to be significant. Continuous data without repeated measurements, such as donor and recipient animals' weights, weight increase of graft, donor compliance, and animal survival, as well as nonparametric data, such as the histologic semiquantitative analysis, were compared with the Mann-Whitney test.

\section{Results}

Donors. Donor and recipient rats were randomly assigned to the four groups (Table I). The mean 


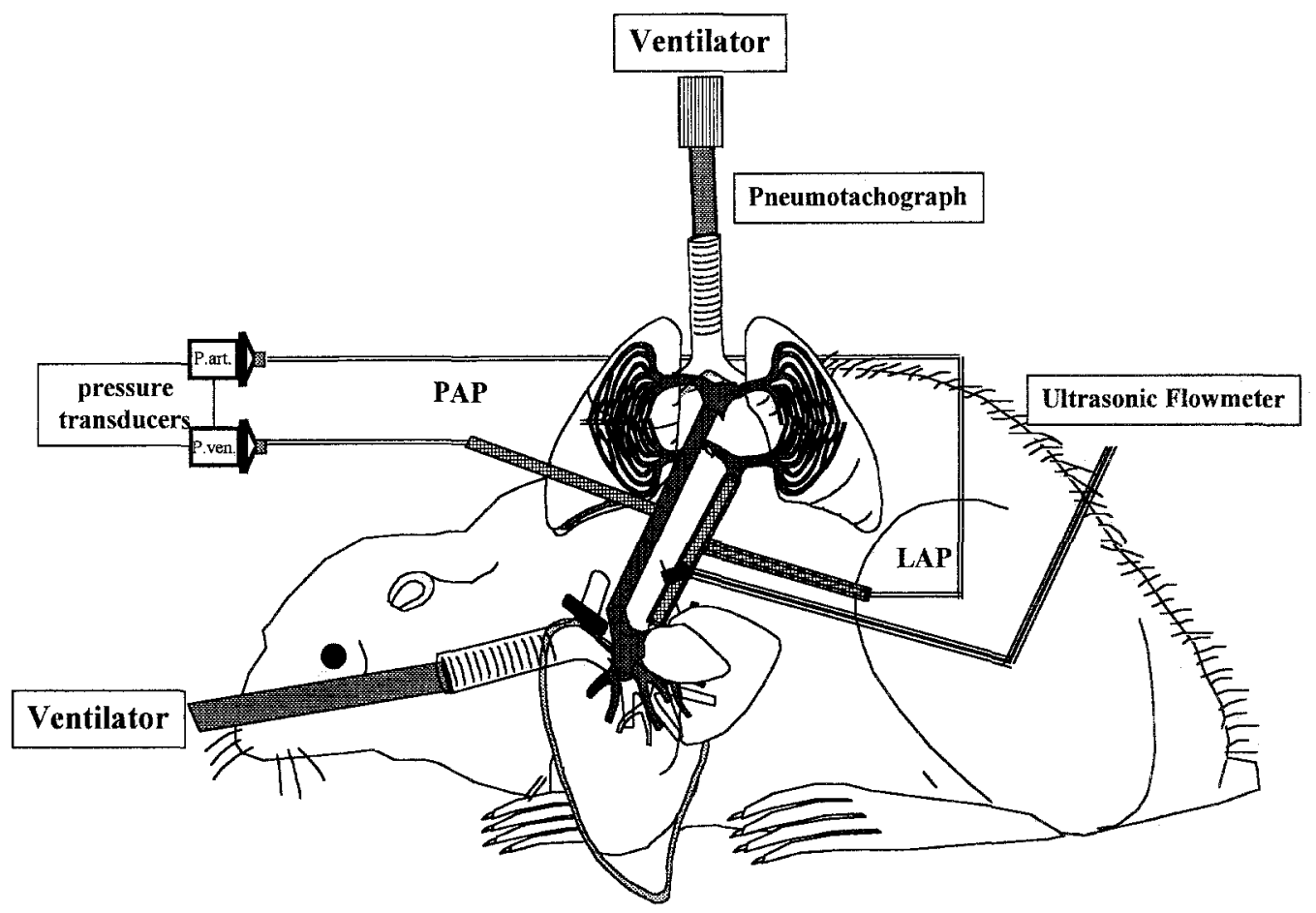

Fig. 1. Experimental setup of the acute double lung transplantation model. A donor lung is connected to a syngeneic recipient animal with two specially designed stents. The donor lung is ventilated separately. A pneumotachograph with analog/digital converters allows isolated determination of donor lung function. The analog/digital converter is connected to a computer for online data recording and display. The side ports of both stents are used for pressure measurement and blood retrieval for gas measurements. PAP, Pulmonary artery pressure; $L A P$, left atrial pressure.

Table I

\begin{tabular}{|c|c|c|c|c|c|}
\hline & \multicolumn{4}{|c|}{ Surfactant treatment } & \multirow[b]{3}{*}{ Statistics (Mann-Whitney test) } \\
\hline & Group I: & Group II: & Group III & Group $V:$ & \\
\hline & Control & Recipient $200 \mathrm{mg} / \mathrm{kg}$ & Donor $20 \mathrm{mg} / \mathrm{kg}$ & Donor $200 \mathrm{mg} / \mathrm{kg}$ & \\
\hline Graft ischemia (hr) & 16 & 16 & 16 & 16 & \\
\hline $\begin{array}{l}\text { Donor lung compliance } \\
\left(\left(\mathrm{ml} / \mathrm{cm} \mathrm{H} \mathrm{H}_{2} \mathrm{O}\right)\right.\end{array}$ & $68 \pm 4 \pm \S$ & $64 \pm 3^{*} \dagger$ & $79 \pm 4 * \S$ & $82 \pm 4+t$ & $\begin{array}{l}{ }^{*} p<0.05, \uparrow p<0.04 \\
\ddagger p<0.03, \S p<0.05\end{array}$ \\
\hline $\begin{array}{l}\text { Donor lung resistance } \\
\left(\mathrm{cm} \mathrm{H}_{2} \mathrm{O} / \mathrm{ml} / \mathrm{sec}\right)\end{array}$ & $245 \pm 20$ & $231 \pm 17$ & $243 \pm 16$ & $277 \pm 28$ & NS \\
\hline Donor weight (gm) & $348 \pm 13$ & $367 \pm 10$ & $346 \pm 14$ & $367 \pm 16$ & NS \\
\hline Recipient weight (gm) & $353 \pm 22$ & $374 \pm 8$ & $347 \pm 32$ & $370 \pm 25$ & NS \\
\hline Survival (min) & $116 \pm 13$ & $113 \pm 4$ & $120 \pm 0$ & $120 \pm 0$ & NS \\
\hline
\end{tabular}

Comparison of nonserial measurements of donor and recipient animal weight, donor dynamic compliance and resistance before perfusioni, and mean survival Donor treatment with surfactant significantly increased the dynamic lung compliance of the graft. All test statistics were done with the Mann-Whitney test. For explanation of footnote symbols, see Statistics column (far right).

total ischemic times were comparable in all groups, as were pretreatment pulmonary resistance. The pulmonary compliance was significantly better in the donor surfactant pretreatment groups (groups III and IV) after surfactant administration than in controls and in group II (Table I).
Recipients. The average length of survival is depicted in Table I. Timing of surfactant administration did not significantly affect survival. Both donor treatment groups (III and IV) survived the 2-hour study period. During the experiment, pronounced amounts of edema were suctioned from the tracheal 


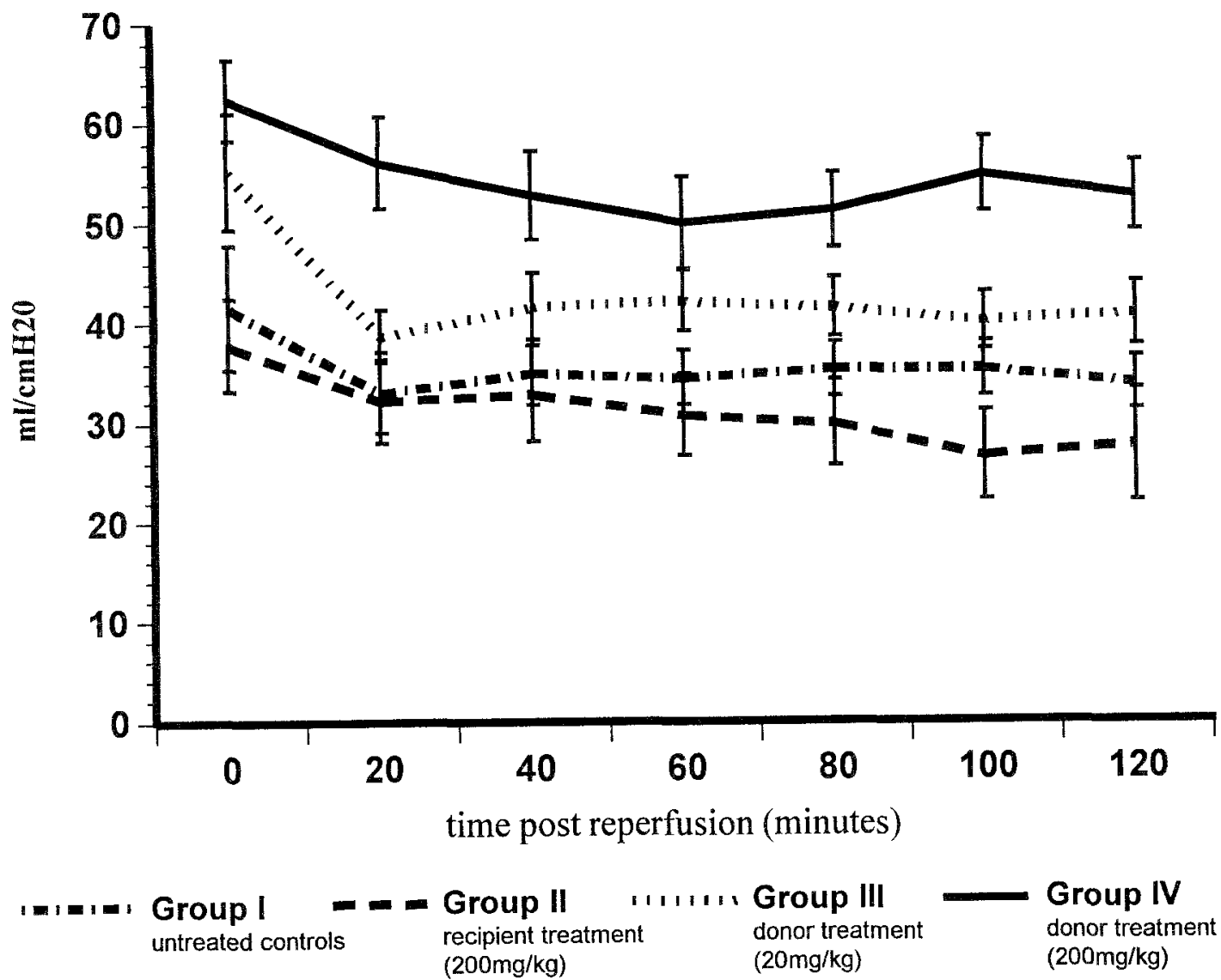

Fig. 2. Dynamic pulmonary compliance measured in 20 -minute intervals. Repeated-measures ANOVA comparison between group I (control group), group II (recipient treatment $200 \mathrm{mg} / \mathrm{kg}$ dose of surfactant), group III (donor treatment $20 \mathrm{mg} / \mathrm{kg}$ dose of surfactant), and group IV (donor treatment $200 \mathrm{mg} / \mathrm{kg} \mathrm{dose}$ of surfactant) (ANOVA: group I vs group IV, $p<0.02$; group II vs group IV, $p<0.04$; group III vs group IV,$p<0.02)$.

tube, mainly in group II, with a total of $22 \pm 2 \mathrm{ml}$ for the entire reperfusion period. This was significantly higher than in group I $(5.7 \pm 1.3 \mathrm{ml}$; Mann-Whitney test: $p<0.001$ ) and group IV $(8.8 \pm 1.3 \mathrm{ml} ; p<0.006)$. No significant difference was noted in the amount of edematous fluid retrieved in group III $(4.4 \pm 0.8 \mathrm{ml})$ and group IV (see above). The weight increase of group II animals was substantially higher $(125 \% \pm 46 \%)$ than that of group IV (78\% $\pm 35 \%$; MannWhitney test: $p<0.05$ ).

Lung function. The pulmonary dynamic compliance was significantly higher in group IV animals (donor treatment, $200 \mathrm{mg} / \mathrm{kg}$ ) than in the recipient treatment group II (repeated-measures ANOVA: $p<0.04$ ) or untreated animals (group I; repeatedmeasures ANOVA: $p<0.02$ ). The increased amount of surfactant administered to group IV animals significantly improved dynamic compliance when comparing with that of group III (donor treatment $20 \mathrm{mg} / \mathrm{kg}$; repeated-measures ANOVA; $p<0.02$ ). Fig. 2 shows a decline in compliance in groups II, III, and IV over the reperfusion period (repeated-measures ANOVA: $p<0.05 ; p<0.001$; $p<0.001$, respectively).

The differences among groups regarding airway resistance were similar to those obtained from dynamic compliance measurements. For example, 60 minutes after reperfusion the animals of group I had a resistance of $678 \pm 54 \mathrm{~cm} \mathrm{H}_{2} \mathrm{O} / \mathrm{L}$ per second versus $648 \pm 110 \mathrm{~cm} \mathrm{H}_{2} \mathrm{O} / \mathrm{L}$ per second in group II and $307 \pm 12 \mathrm{~cm} \mathrm{H}_{2} \mathrm{O} / \mathrm{L}$ per second in group IV. The repeated-measures ANOVA was $p<0.04$ in group IV versus group I and $p<0.05$ in group IV versus group II (Fig. 3). The airway resistance was significantly lower in $200 \mathrm{mg}$ donor treatment than 


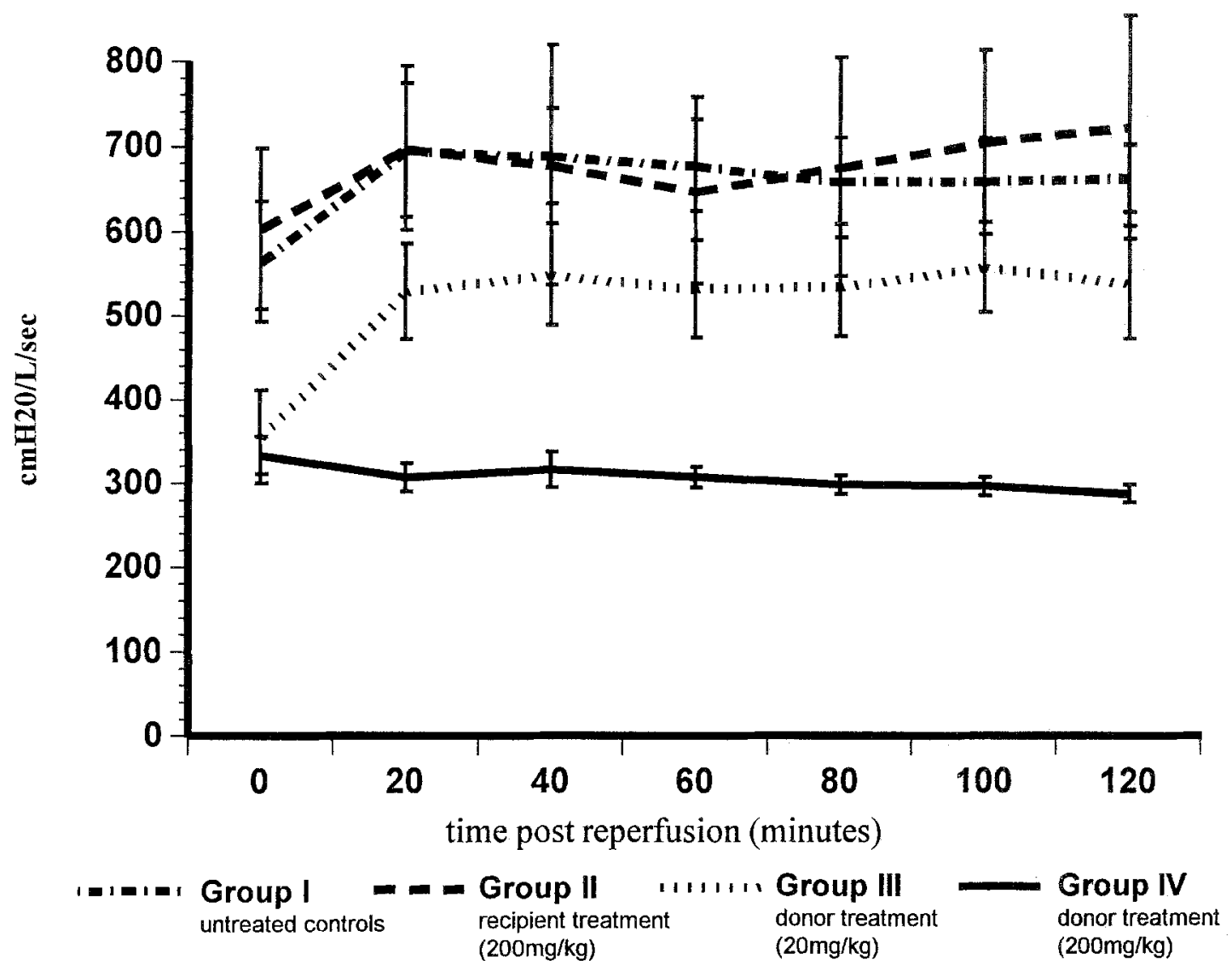

Fig. 3. Resistance to pulmonary air flow measured in centimeters of water per liter per second. Repeated-measures ANOVA for group effect: group I versus group IV, $p<0.04$; group II versus group IV, $p<0.05 ;$ group III versus group IV, $p<0.02$.

with $20 \mathrm{mg}$ donor treatment (repeated-measures ANOVA: $p<0.02$ ).

The arterial-alveolar oxygen difference was severely impaired in untreated grafts (group I). The alveolar-arterial oxygen difference of group IV was significantly lower than that of all other groups (repeated-measures ANOVA to group I, $p<0.05$; to group II, $p<0.02$ ). Again, the increased dose of surfactant provided better oxygenation when compared with that of group III (repeated-measures ANOVA: $p<0.01$ ). Fig. 4 shows a constant and significant increase of the alveolar-arterial oxygen difference in all groups (repeated-measures ANOVA to group I, $p<0.001$; to group II, $p<0.04$; to group III, $p<0.0001$; to group IV, $p<0.003$ ).

Finally, the pulmonary vascular resistance was significantly lower after donor treatment with 200 $\mathrm{mg} / \mathrm{kg}$ than that in groups I and II (repeatedmeasures ANOVA: $p<0.05$ and $p<0.04$, respec- tively). The pulmonary vascular resistance in group III was not significantly different from that in group IV. Fig. 5 shows a significant decline in the pulmonary vascular resistance in groups II and IV (repeated-measures ANOVA: $p<0.04, p<0.0006$, respectively).

Histology. The results of the blinded histologic semiquantitative analysis of the specimens from the four experimental groups are summarized in Table II. It is noteworthy that granulocyte infiltration was practically negligible in all groups. Despite the significant differences in hemodynamic and lung function analysis, as well as weight increase, among the individual groups, the pronounced graft edema is not reflected in the twodimensional histologic assessment. Only the degree of pulmonary hemorrhage was significantly increased in group II when compared with group IV (Mann-Whitney: $p<0.05$ ). 
The Journal of Thoracic and

Cardiovascular Surgery

Volume 113 , Number 6

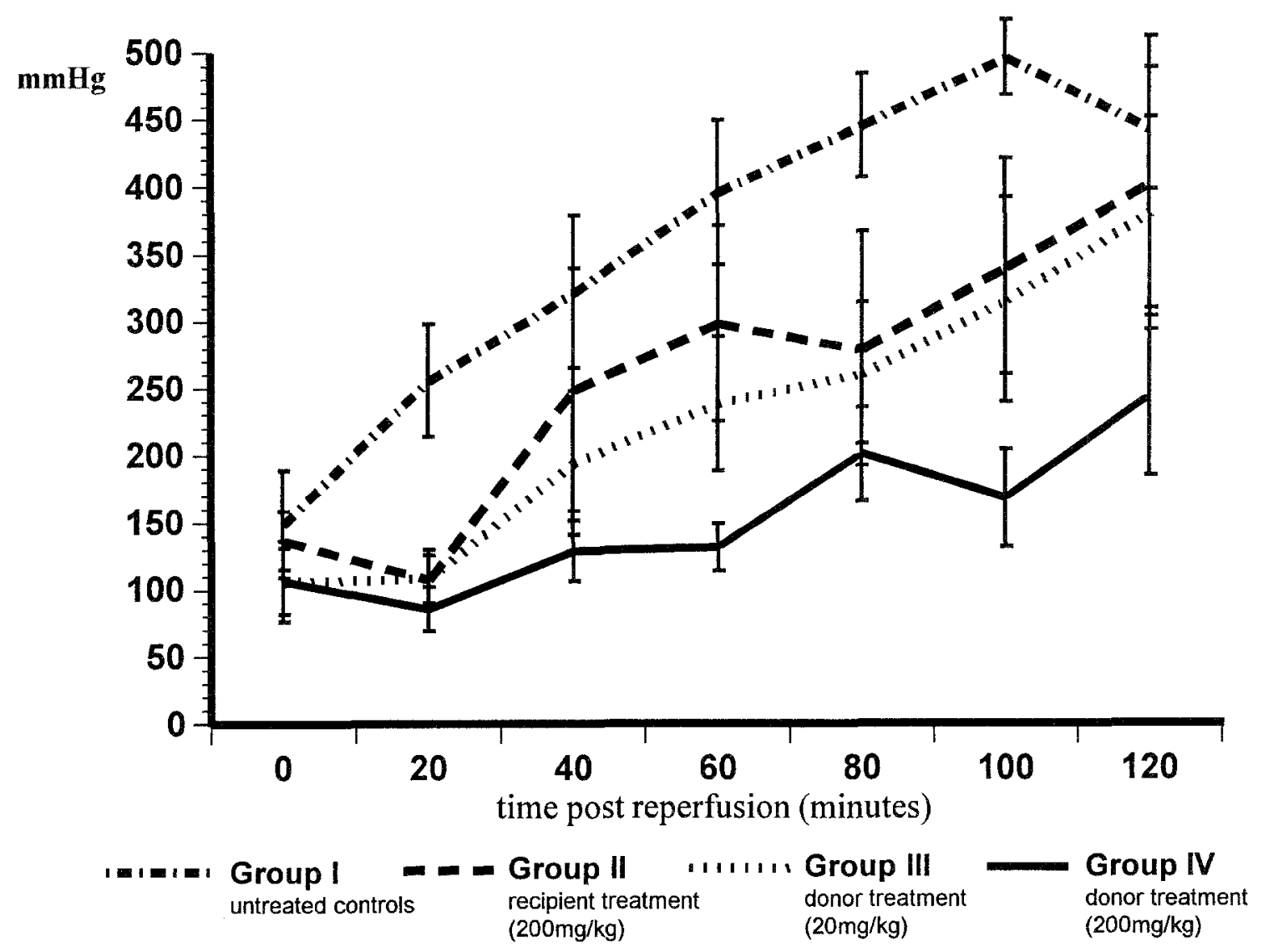

Fig. 4. Comparison of alveolar-arterial oxygen difference. Donor treatment with exogenous surfactant with either 20 or $200 \mathrm{mg} / \mathrm{kg}$ improves graft function with respect to oxygenation (group I vs group IV, $p<$ 0.05; group II vs group IV, $p<0.02$; group III vs group IV, $p<0.01$ ).

\section{Discussion}

Ischemia-reperfusion injury is one of the main causes of early morbidity and mortality in clinical lung transplantation. Various factors have been made responsible for this severe postoperative complication, one of which is related to ischemia-induced surfactant dysfunction and depletion. Experimental studies by Andrade, ${ }^{4}$ Veldhuizen, ${ }^{3}$ and their colleagues have provided ample data that underline this observation. These changes are evident immediately after flush perfusion and increase in severity during storage. So far it seems that these alterations in the surfactant system cannot be avoided. Therefore various authors have introduced exogenous surfactant replacement therapy to lung transplantation. In a 38-hour ischemia experiment by Novick and colleagues, ${ }^{11}$ the results after exogenous surfactant treatment were generally positive, but not always persistent. Clinically, Strüber and coworkers used nebulized surfactant for a single patient with early signs of ischemia-reperfusion injury and were able to reverse the course and avoid further tissue damage. On the basis of the presently available data, it remains unclear whether donor or recipient replacement therapy with exogenous surfactant can achieve the best results.

According to the results obtained in the study presented here, exogenous surfactant replacement therapy in the donor before organ perfusion can significantly improve graft function after extended ischemia when compared with results in untreated controls or treatment of the donors lungs immediately before implantation, referred to in this text as recipient treatment. The results are persistent and highly significant. Compared with untreated controls or the recipient treatment group, the donor treatment group (group IV) had increased pulmonary compliance, resistance, and oxygenation and decreased pulmonary vascular resistance. The positive effect of donor surfactant treatment is dose- 


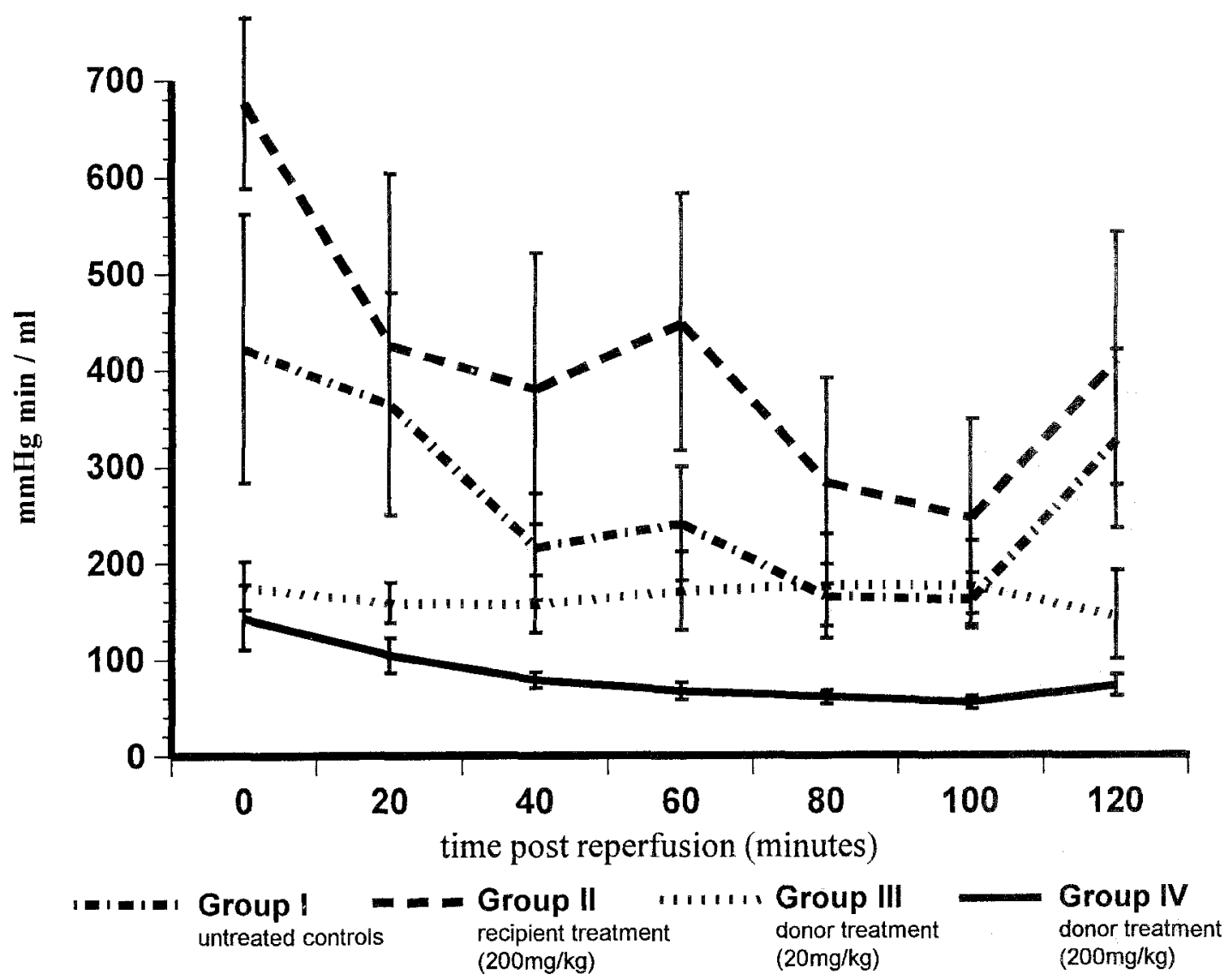

Fig. 5. The vascular resistance to pulmonary blood flow measured in millimeters of mercury per minute per milliliter is markedly elevated in group I and group II. Pulmonary vascular resistance changed significantly over time in group I (repeated-measures ANOVA: $p<0.05)$, group II $(p<0.04)$, and group IV $(p<0.0006)$. Repeated-measures ANOVA for group effect: group I versus group IV, $p<0.05$; group II versus group IV, $p<0.04$; group III versus group IV, $p<0.3$.

Table II

\begin{tabular}{|c|c|c|c|c|c|}
\hline & \multicolumn{4}{|c|}{ Surfactant treatment } & \multirow[b]{3}{*}{ Statistics (Mann-Whitney test) } \\
\hline & Group I: & Group II: & Group III: & Group IV: & \\
\hline & Control & Recipient $200 \mathrm{mg} / \mathrm{kg}$ & Donor $20 \mathrm{mg} / \mathrm{kg}$ & Donor $200 \mathrm{mg} / \mathrm{kg}$ & \\
\hline Granulocyte infiltration & $1 \pm 0$ & $1 \pm 0$ & $1 \pm 0$ & $1 \pm 0$ & NS \\
\hline Pulmonary hemorrhage & $1.8 \pm 0.8$ & $2.3 \pm 1.0$ & $1.6 \pm 0.8$ & $1.3 \pm 0.5$ & $\begin{array}{l}p<0.05 \\
\text { (II vs IV) }\end{array}$ \\
\hline Interstitial edema & $1.3 \pm 0.5$ & $1.4 \pm 0.5$ & $1.3 \pm 0.4$ & $1.3 \pm 0.5$ & NS \\
\hline Intraalveolar edema & $2.0 \pm 0.9$ & $1.8 \pm 0.4$ & $1.9 \pm 0.5$ & $1.8 \pm 0.4$ & NS \\
\hline
\end{tabular}

Semiquantitative histologic assessment of lung specimens after the end of reperfusion. Pulmonary hemorrhage was significantly more pronounced in group II compared to group IV (Mann-Whitney test, $p<0.05$ ). Score: $1=$ no, $2=$ mild, $3=$ moderate, $4=$ severe .

dependent, with gradual improvements of graft function. Positive effects regarding preservation of graft function may be seen with as little as $20 \mathrm{mg} / \mathrm{kg}$ of surfactant given to the donor before organ perfusion. Recipient treatment was advantageous only in comparison with the untreated controls with respect to improvements of the alveolar-arterial oxygen difference.

Despite these striking hemodynamic and oxygenation differences between individual treatment regimens, the histologic changes were only modest. Perhaps longer reperfusion periods to show distinct 
changes or more sophisticated methods of analysis are required for this model.

Potential mechanisms of surfactant-related lung dysfunction have been recently addressed by Novick and coworkers. ${ }^{16}$ Alveolar type II cells play a multifaceted role in determining alveolar integrity under physiologic conditions and during evolving lung injury. From surfactant replacement studies in patients with an adult respiratory distress syndrome, it is known that exogenous surfactant instillation leads to recruitment of atelectatic alveoli, as well as increased distention of existing air spaces. Both increase the effective lung volume, lower the arterial-alveolar oxygen gradient, and decrease arteriovenous shunting. ${ }^{17}$ As a result of the EulerLiljestrand reflex, previously atelectatic and malperfused lung tissue is then uniformly and effectively perfused. This is extremely important for the phase of organ flush perfusion with chilled preservation solutions, because it ensures an even distribution of the protective media throughout the entire lung. ${ }^{18}$ Improved preservation may be one reason that the donor treatment in this study was so much more effective than the recipient treatment after ischemia.

According to studies by Erasmus and colleagues, ${ }^{19}$ the surfactant pool is inversely proportional to time of cold ischemia. Because of the remaining activity of phospholipase, the valuable endogenous surfactant pool may be significantly reduced before the beginning of reperfusion. Consequently, this leads to atelectasis ${ }^{3}$ and inhomogeneous reperfusion. ${ }^{18}$ Anaerobic metabolism can trigger the complement cascade and result in additional tissue damage. The administration of surfactant immediately before reperfusion may then be too late to improve overall lung function owing to irreversible lung damage. Also, the accumulation of plasma proteins during ischemia through damaged cell membranes can immediately deactivate the endogenous and the exogenous surfactant pool. ${ }^{8}$ Prophylactic and preventive donor treatment limits membrane damage and complement activation and thus preserves the exogenous and endogenous surfactant pool.

The adult human and animal surfactant pool size is in the range of 3 to $15 \mathrm{mg} / \mathrm{kg}$. Exogenous surfactant administration results in an uptake of more than $60 \%$ of the surfactant dose into the alveolar type II cells of normal rabbit lungs. ${ }^{20}$ This results in a significant net increase of the overall surfactant secretion for at least 10 hours after instillation. ${ }^{21}$ Surfactant treatment therefore has a long-lasting effect.
In most animal models the donor lung must be considered perfectly normal. In the clinical situation the negative impact of brain death, hemodynamic instability, infection, trauma, and extended ventilation with possible barotrauma can result in surfactant depletion and therefore significant dysfunction of the donor lung. ${ }^{22}$ This may underline the importance of early exogenous surfactant treatment.

Exogenous surfactant supplementation is presently costly and most likely not available as a routine procedure for a donor lung in clinical transplantation. This study has shown a hemodynamic and oxygenation benefit with as little as $20 \mathrm{mg} / \mathrm{kg}$ of surfactant given as a bolus to the donor intratracheally. This form of treatment should be considered for donor lungs after extended ventilation periods before harvesting. Critical and borderline pulmonary grafts with atelectasis or edema may benefit from this treatment and thus be rendered suitable for transplantation. Future studies should assess endogenous surfactant phospholipid quantity and composition in donor lungs to help distinguish those grafts that would benefit most from surfactant supplementation. In addition, it will be important to sort out which mechanism is most predominant in caùsing altered surfactant function after lung transplantation.

To conclude, this study has shown a significant benefit on graft function after donor versus recipient treatment with exogenous surfactant. After an extended ischemic interval of 16 hours, the pulmonary function of the transplanted graft was well preserved. In addition, donor surfactant treatment is dose-dependent. Positive effects may be seen with as little as $20 \mathrm{mg} / \mathrm{kg}$ of exogenous surfactant given before donor organ perfusion.

We thank Dr. Jerry Halpern, Senior Scientist in the Division of Biostatistics, Department of Health Research and Policy at Stanford University, for his support in the statistical evaluation of the data. The help provided by Dr. Heike Hausen in preparation of the manuscript is greatly appreciated.

\section{REFERENCES}

1. Cooper JD, Vreim CE. National Heart, Lung, and Blood Institute workshop summary. Biology of lung preservation for transplantation. Am Rev Respir Dis 1992;146:803-7.

2. Waldhausen JA, Giammona ST, Kilmann JW, Daly WJ. Effect of transplantation of canine lung on pulmonary compliance and surfactant. JAMA 1965;191:1002-5.

3. Veldhuizen RA, Lee J, Sandler D, et al. Alterations in pulmonary surfactant composition and activity after experi- 
mental lung transplantation. Am Rev Respir Dis 1993;148: 208-15.

4. Andrade R, Solien EE, Wangensteen OD, Tsal MY, Kshettry VR, Bolman RM. Surfactant dysfunction in lung preservation. Transplantation 1995;60:536-41.

5. Akashi A, Nakahara K, Kamiike W, et al. Attenuation of warm ischemic injury of rat lung by inflation with room air-assessment of cellular components and the surfactant in the bronchoalveolar lavage fluid in relation to changes in cellular adenosine triphosphate. Transplantation 1993;55:2430.

6. Hausen B, Ramsamooj R, Hewitt CW, et al. Importance of static lung inflation during organ storage: impact of varying ischemic intervals in a double lung rat transplantation model. Transplantation 1996;62:1720-5.

7. Seeger W, Grube C, Gunther A, Schmidt R. Surfactant inhibition by plasma proteins: differential sensitivity of various surfactant preparations. Eur Respir J 1993;6:971-7.

8. Kobayashi T, Nitta K, Ganzuka M, Inui S, Grossmann G, Robertson B. Inactivation of exogenous surfactant by pulmonary edema fluid. Pediatr Res 1991;29:353-6.

9. DeCampos KN, Waddell TK, Slutsky AS, et al. Functional and biochemical assessment of postpreservation lung viability in a rat model. J Appl Physiol 1994;76:813-20.

10. Novick RJ, Possmayer F, Veldhuizen RA, Menkis AH, McKenzie FN. Surfactant analysis and replacement therapy: A future tool of the lung transplant surgeon? Ann Thorac Surg 1991:52:1194-200.

11. Novick RJ, Veldhuizen RA, Possmayer F, Lee J, Sandler D, Lewis JF. Exogenous surfactant therapy in thirty-eight-hour lung graft preservation for transplantation. J Thorac Cardiovasc Surg 1994;108:259-68.

12. Hausen B, Demertzis S, Schroeder F, Beuke M, Schaefers HJ. Double lung transplantation in the rat: an acute, syngeneic in situ model. Ann Thorac Surg 1996;61:184-9.

13. Steen S, Sjoberg T, Massa G, Ericsson L, Lindberg L. Safe pulmonary preservation for 12 hours with low-potassiumdextran solution. Ann Thorac Surg 1993;55:434-40.

14. Milliken GA. Analysis of repeated measures designs. In: Berry DA, editor. Statistical methodology in the pharmaceutical sciences. New York: Dekker; 1990.

15. Strüber M, Cremer J, Harringer W, Hirt SW, Costard Jackle A, Haverich A. Nebulized synthetic surfactant in reperfusion injury after single lung transplantation. $\mathbf{J}$ Thorac Cardiovasc Surg 1995;110:563-4.

16. Novick RJ, Gehman KE, Ali IS, Lee J. Lung preservation: the importance of endothelial and alveolar type II cells integrity. Ann Thorac Surg 1996;62:302-14.

17. Goldsmith LS, Greenspan JS, Rubenstein SD, Wolfson MR, Shaffer TH. Immediate improvement in lung volume after exogenous surfactant: alveolar recruitment versus increased distention. J Pediatr 1991;119:424-8.

18. Baretti R, Bitu Moreno J, Beyersdorf F, Matheis G, Fran- cischetti I, Kreitmayr B. Distribution of lung preservation solutions in parenchyma and airways: influence of atelectasis and route of delivery. J Heart Lung Transplant 1995;14:8091.

19. Erasmus ME, Petersen AH, Oetomo SB, Prop J. The function of surfactant is impaired during the reimplantation response in rat lung transplants. J Heart Lung Transplant 1994;13:791-802.

20. Rider ED, Ikegami M, Jobe AH. Localization of alveolar surfactant clearance in rabbit lung cells. Am J Physiol 1992;263:L201-9.

21. Oetomo SB, Lewis J, Ikegami M, Jobe AH. Surfactant treatments alter endogenous surfactant metabolism in rabbit lungs. J Appl Physiol 1990;68:1590-6.

22. Pison U, Seeger W, Buchhorn R, et al. Surfactant abnormalities in patients with respiratory failure after multiple trauma. Am Rev Respir Dis 1989;140:1033-9.

\section{Discussion}

Dr. Richard J. Novick (London, Ontario, Canada). In a recent article we have shown exactly the same thing in a canine model-that the donors must be treated with surfactant to get an optimal result. That is one of the themes that is emerging.

It is also important to look at the types of surfactant. The large aggregates are the metabolic precursors of the small aggregates; the large aggregates are surface active and are effective; the small aggregates do not reduce surface tension. Did you have a chance to look at the small-to-large aggregate ratio in lung lavages from the transplanted animals?

Finally, concerning cost, the standard dose that has been used in adult respiratory distress syndrome and lung injury studies is $100 \mathrm{mg} / \mathrm{kg}$. If one expects to transplant one lung graft, $50 \mathrm{mg} / \mathrm{kg}$ may well be enough; as you have shown, even $20 \mathrm{mg} / \mathrm{kg}$ provides some benefit. I think the cost of surfactant will decline with time, and it may be affordable if it is shown to be effective when administered as a single shot to donors.

Dr. Hausen. Thank you for your comments. In these experiments we have not looked at the lavage as we have added surfactant. We thought that doing so would confuse our results. In other previously performed experiments, however, we have looked at the small-to-large aggregate ratio and seen significant differences that actually made us think about this type of treatment. We chose $200 \mathrm{mg}$ from the literature. Concerning trials with adult respiratory distress syndrome, and even using $20 \mathrm{mg}$, the costs may amount to around $\$ 10,000$ per patient; $50 \mathrm{mg}$ would be $\$ 25,000$. I do not know whether the American system can rectify these costs. We, in Germany, could not. 